\title{
Etodolac, a selective cyclooxygenase-2 inhibitor, inhibits liver metastasis of colorectal cancer cells via the suppression of MMP-9 activity
}

\author{
TETSUO ISHIZAKI, KENJI KATSUMATA, AKIHIKO TSUCHIDA, TATEHIKO WADA, \\ YASUHARU MORI, MASAYUKI HISADA, HIDEAKI KAWAKITA and TATSUYA AOKI
}

Third Department of Surgery, Tokyo Medical University, Tokyo, Japan

Received October 18, 2005; Accepted November 28, 2005

\begin{abstract}
Synchronous or metachronous liver metastasis occurs in approximately $15 \%$ of colorectal cancer patients and is an important negative prognostic factor. We therefore need an effective therapy to prevent metastasis. It has become apparent that cyclooxygenase (COX)-2 plays an important role in cancer growth, invasion and metastasis and that there is potential for chemoprevention via inhibition of these processes. We injected colon 26, a colorectal cancer cell line, in CDF1 mouse spleen and, from the following day, two kinds of COX-2 inhibitor (etodolac and nimesulide) were administered orally. Two weeks later, the animals were sacrificed, the liver was excised, and we counted the number of metastatic nodules on the liver surface. In addition, COX-2 mRNA, matrix metalloproteinase (MMP)-9 mRNA, and tissue inhibitor of MMP (TIMP)-1 mRNA of cancer tissue were measured by means of real-time RT-PCR. The number of metastatic nodules on the liver surface was significantly lower in the etodolac-treated group than in controls $(\mathrm{p}=0.001)$, but no significant difference was noted in the nimesulide-treated group. The expression of COX-2 mRNA was also significantly lower in the etodolactreated group than in controls $(\mathrm{p}=0.04)$, but not in the nimesulide-treated group. In addition, the expression of MMP-9 mRNA was significantly lower in the etodolac group than in controls $(\mathrm{p}=0.02)$, but not in the nimesulide group. Among the groups, there were no significant differences in TIMP-1 mRNA. Expression of COX-2 mRNA and MMP-9 mRNA correlated significantly $(\mathrm{r}=0.78, \mathrm{p}=0.001)$, but there was no correlation between either COX-2 mRNA and TIMP-1 mRNA expression or between MMP-9 mRNA and TIMP-1 mRNA expression. These findings indicate that the selective COX-2 inhibitor, etodolac, suppresses liver metastasis by reducing MMP-9 activity.
\end{abstract}

Correspondence to: Dr Akihiko Tsuchida, Third Department of Surgery, Tokyo Medical University, 6-7-1 Nishi-Shinjuku, Shinjukuku, Tokyo 160-0023, Japan

E-mail: akibobo@hotmail.com

Key words: colorectal cancer, liver metastasis, MMP-9, TIMP-1, COX-2 inhibitor

\section{Introduction}

Cyclooxygenase (COX) is a rate-limiting enzyme synthesized from prostaglandin $(\mathrm{PG})$, and it exists in three isoforms. COX-1 is manifested constitutively in most organs. COX-2 is induced by various cytokines or growth factors. COX-3 is found in brain tissue and is related to pain. In previous studies, conspicuously greater COX-2 expression has been found in many human cancer tissues compared to normal tissue, indicating that COX-2 plays an important role in tumorigenesis and cancer growth or progression (1). In a number of animal studies, it has been demonstrated that non-steroidal anti-inflammatory drugs (NSAIDs), COX inhibitors, suppress carcinogenesis (2). Epidemiologically, it has been shown that among long-term aspirin users, the mortality rate due to colorectal cancer is $40-50 \%$ lower than in natural controls (3). Recently, several researchers reported that COX-2 inhibitor suppresses liver or lung metastasis in animal models of colorectal cancer cell lines (4-9). These findings suggest that COX inhibitors are promising candidates for chemoprevention, but the mechanism has not yet been elucidated in detail.

Synchronous or metachronous liver metastasis is recognized in $10-15 \%$ of all colorectal cancer patients, and is a vital factor in prognosis. Surgery is aggressively performed for liver metastasis but no effective therapy has been established for the prevention of liver metastasis. For liver metastasis of colorectal cancer, several steps are required. Firstly, cancer cells detach from the primary lesion and then, by the action of matrix metalloproteinase (MMP), an extracellular matrix (ECM)-degrading enzyme, degrade and invade the ECM or basement membrane, and enter the blood vessels. Then, cancer cells in circulating blood adhere to the endothelium of hepatic blood vessels. Similarly, by the action of MMP, cancer cells degrade the basement membrane of the blood vessel and invade outside the blood vessels $(10,11)$. Cancer cells that have migrated outside the blood vessels move to within stroma while degrading ECM and, concurrently with angiogenesis, growing to form metastatic lesions. In this process, MMP expression increases in the endothelial cells of the blood vessel, causing degradation of the basement membrane in the surrounding neovascularization, thereby creating an ideal environment for the formation of metastatic lesions (12). MMP is classified into the following five groups on the basis of sequence homology and substrate specificity: 
collagenases, gelatinases, stromelysins, membrane-type metalloproteinase (MT-MMP) and non-classified MMPs (13). Approximately $90 \%$ of collagen, the main constituent of ECM, is of type I, and it is degraded by collagenase (MMP-1, -8, -13). Type IV collagen, which is characteristic of basement membrane, is degraded by MMP-2, -3, -7, -9 and -10 . It is reported that, of these MMPs, MMP-2 and MMP-9 have been found, in examinations using various cell lines, to be associated with cancer migration, invasion and metastasis (13). On the contrary, the tissue inhibitor of MMP (TIMP) was originally identified as an MMP inhibitor. Four kinds of TIMPs have been described: TIMP-1, $-2,-3$ and -4 . TIMP-1 inhibits most interstitial collagenases and MMP-9. TIMP-2 binds specifically and non-covalently to the proform of MMP-2 and inhibits its enzyme activity. Thus, TIMPs are selective inhibitors of MMP activity, and degradation of basement membrane and ECM can be explained in terms of the balance between MMPs and TIMPs (14). However, previous studies have shown that enhanced expression of TIMPs is correlated with progressive cancer (15). Further studies are required on the mechanisms of TIMPs.

Since MMPs contribute markedly to cancer invasion, metastasis and angiogenesis, they can be regarded as promising targets for prevention of hepatic metastasis or recurrence. It has been frequently reported that, in cancer cell lines, COX-2 inhibitor is associated with invasion and metastasis from the primary lesion via the expression of MMP (16-19). However, there are very few reports on the relationships between COX-2 inhibitor and MMPs or TIMPs in hepatic metastasis of colorectal cancer (5-8). Therefore, we investigated the inhibitory effects of 2 kinds of COX-2 inhibitor and their relationships with MMP-9 and TIMP-1 using a mouse hepatic metastasis model.

\section{Materials and methods}

Drugs. Etodolac (1,8-diethy-1,3,4,9-tetrahydropyrano [3,4-b] indole-lacetic acid), a selective COX-2 inhibitor, was kindly supplied by Nippon Shinyaku Co., Ltd. (Kyoto, Japan). We purchased and used another COX-2 inhibitor, nimesulide (N-[4-nitro-2-phenoxyphenyl]-methanesulfonamide) (Sigma Chemical Co., St. Louis, MO, USA). These drugs were dissolved in $1 \%$ CM-cellulose solution.

Cell culture. Colon 26 cells, derived from human colorectal cancer, were obtained from Tsukuba ARL (Tsukuba, Japan) and maintained in RPMI-1640 supplemented with 10\% FBS, $0.01 \%$ antibiotics and antimyotics.

Animal experimental design. Male CDF1 mice (Charles River, Kanagawa, Japan) aged 6 weeks and weighing 20-25 g were used in experiments after being acclimated for 1 week. The animals were anesthetized with ketamine hydrochloride and xylazine hydrochloride. A small incision of approximately $1 \mathrm{~cm}$ was made at the left side of the abdomen and the spleen was drawn outside the body. Next, $1 \times 10^{4}$ cell $/ 50 \mathrm{ml}$ of colon 26 cell suspension adjusted at PBS was injected into the spleen, and the abdomen was closed. Etodolac $(20 \mathrm{mg} / \mathrm{kg}$ ) or nimesulide $(30 \mathrm{mg} / \mathrm{kg}$ ) was mixed in with powdered feed, which was then given for oral ingestion from the next day.

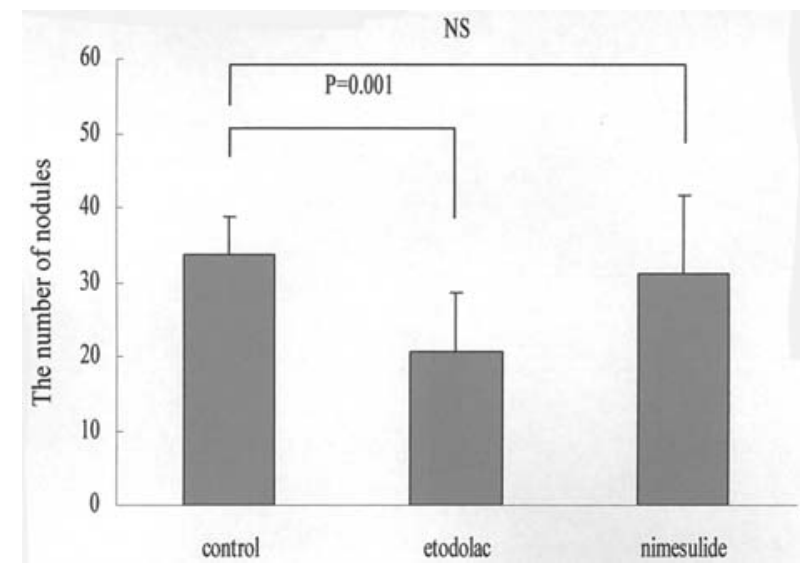

Figure 1. The number of metastasic nodules. There was a significant reduction in the etodolac group $(15.7 \pm 5.3$ nodules) compared with the control group $(33.7 \pm 5.2)(\mathrm{p}=0.0001)$. No significant difference was noted in the nimesulide group (31.1 \pm 10.4$)$.

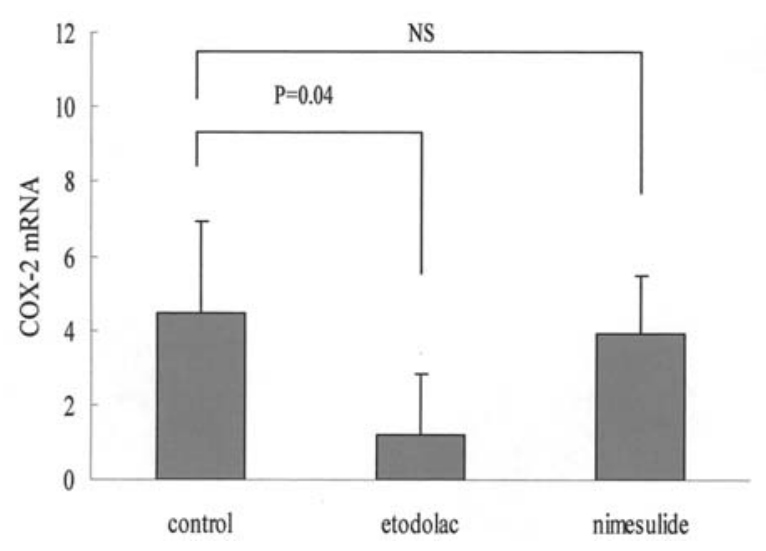

Figure 2. COX-2 mRNA expression. There was a significant reduction in the etodolac group $(1.2 \pm 1.7)$ compared with the control group $(4.5 \pm 2.5)$ $(\mathrm{p}=0.04)$. No significant difference was noted in the nimesulide group $(3.9 \pm 1.6)$.

Two weeks later, the animals were sacrificed, the liver was resected and the number of metastatic nodules on the liver surface was counted. For mRNA measurement, $20 \mathrm{mg}$ of cancer tissue was retrieved and immediately preserved, frozen at $-80^{\circ} \mathrm{C}$. Three groups were formed: a control group consisting of 10 mice in which COX-2 inhibitor was not used; an etodolac-treated group of 10 mice and a nimesulide-treated group of 10 mice. Animal experiments were conducted in accordance with the guidelines for animal experiments of Tokyo Medical University.

Real-time RT-PCR analysis. Total RNA was extracted from approximately $20 \mathrm{mg}$ of cancer tissue by means of the RNeasy Protect Mini Kit (50) (Qiagen; Valencia, CA, USA). Using 500 ng of extracted total RNA, cDNA was synthesized in $50 \mathrm{ml}$ of reactive fluid containing 10X random primer (Applied Biosystems; Foster City, CA, USA), dNTP Mix 100 mM, 10X RT buffer, and $50 \mathrm{U} / \mathrm{ml}$ of MultiScribe reverse transcriptase, after the reactive fluid had been maintained at a constant temperature of $50^{\circ} \mathrm{C}$ for $2 \mathrm{~min}, 95^{\circ} \mathrm{C}$ for $10 \mathrm{~min}, 95^{\circ} \mathrm{C}$ 


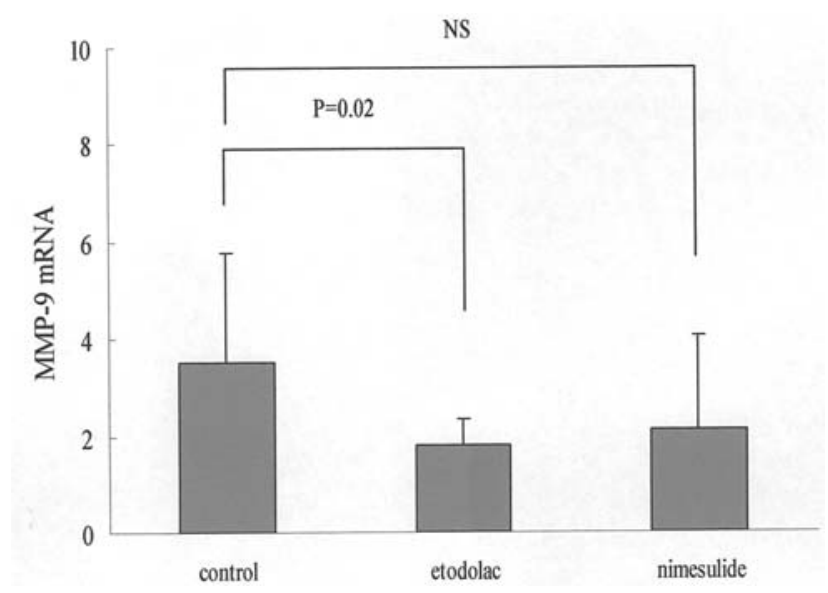

Figure 3. MMP-9 mRNA expression. There was a significant reduction in the etodolac group $(1.7 \pm 0.5)$ compared with the control group $(3.5 \pm 2.2)(\mathrm{p}=0.02)$. No significant difference was noted in the nimesulide group $(2.1 \pm 1.9)$.

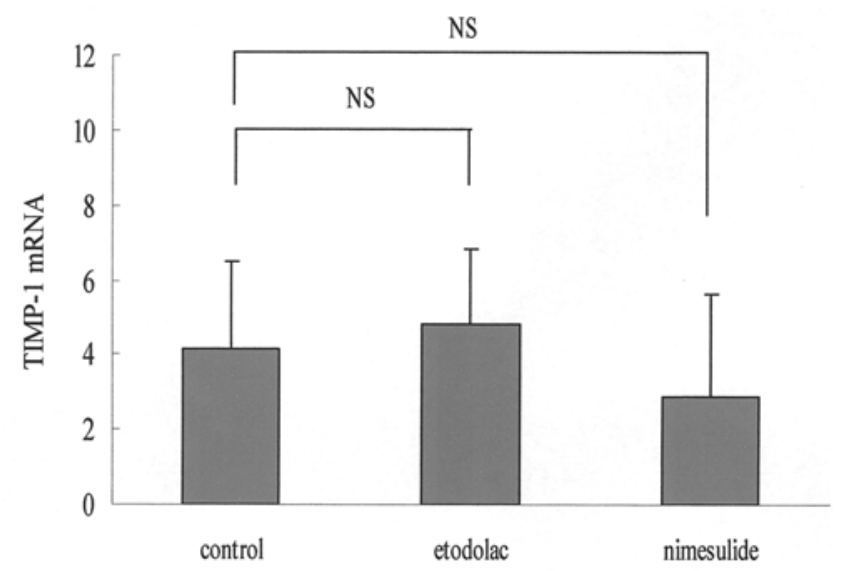

Figure 4. TIMP-1 mRNA expression. In the etodolac group (4.8 \pm 2.0$)$ and in the nimesulide group, no significant difference from the control group (4.2 \pm 2.4$)$ was recognized.

for $15 \mathrm{sec}$ or $60^{\circ} \mathrm{C}$ for $1 \mathrm{~min}$. Following cDNA synthesis, realtime PCR was performed using TaqMan gene expression assay (Applied Biosystems; COX-2: Mm00478374_ml, MMP-9: Mm00600163_ml, TIMP-1: Mm00441818_ml). Fluorescence of isolated reporter pigment was detected by ABI PRISM 7000 Sequence Detection System (Applied Biosystems). A comparative investigation was performed of the expression of COX-2 mRNA, MMP-9 mRNA and TIMP-1 mRNA in hepatic metastatic lesion.

Statistical analysis. All results were indicated as means \pm SD. Student's t-test was used for statistical analysis. A p-value of $<0.05$ was judged to indicate a statistically significant difference. The relationships among COX-2 mRNA, MMP-9 mRNA and TIMP-1 mRNA were calculated by the Spearman rank correlation coefficient.

\section{Results}

Number of metastatic nodules. Two weeks after a colon 26 cell suspension of $1 \times 10^{4}$ cell $/ 50 \mathrm{ml}$ was injected into the CDF1

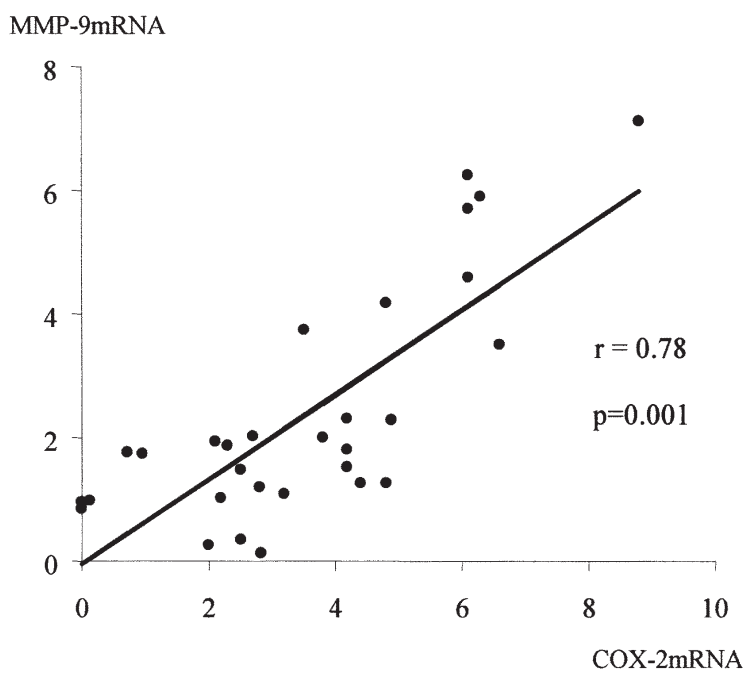

Figure 5. There was a significant correlation between expression of COX-2 mRNA and MMP-9 mRNA $(\mathrm{r}=0.78, \mathrm{p}=0.001)$.

mouse spleen, the liver was resected, and the number of metastatic nodules on the liver surface was counted. The number was $33.7 \pm 5.2$ nodules in the control group, $15.7 \pm 5.3$ in the etodolac-treated group and $31.1 \pm 10.4$ in the nimesulidetreated group (Fig. 1). There was a significant reduction in the etodolac-treated group compared with controls $(\mathrm{p}=0.001)$, but no significant difference was noted in the nimesulidetreated group.

COX-2 mRNA expression by real-time RT-PCR. RNA was extracted from approximately $20 \mathrm{mg}$ of cancer tissue by means of the RNeasy Protect Mini Kit, and cDNA was synthesized. From this, COX-2 mRNA was measured by means of TaqMan gene expression assay. The expressions of COX-2 mRNA in each group were as follows: $4.5 \pm 2.5$ in the control group, $1.2 \pm 1.7$ in the etodolac-treated group and $3.9 \pm 1.6$ in the nimesulide-treated group (Fig. 2). There was a significant reduction in the etodolac-treated group compared with controls $(p=0.04)$, but no significant difference was noted in the nimesulide-treated group.

MMP-9 mRNA expression by real-time RT-PCR. RNA was extracted from approximately $20 \mathrm{mg}$ of cancer tissue, cDNA was synthesized and MMP-9 mRNA was measured. The expressions of MMP-9 mRNA in each group were as follows: $3.5 \pm 2.2$ in the control group, $1.7 \pm 0.5$ in the etodolac-treated group and 2.1 \pm 1.9 in the nimesulide-treated group (Fig. 3). There was a significant reduction in the etodolac-treated group compared with controls $(\mathrm{p}=0.02)$, but there was no significant difference in the nimesulide-treated group.

TIMP-1 mRNA expression by real-time RT-PCR. RNA was extracted from approximately $20 \mathrm{mg}$ of cancer tissue, cDNA was synthesized and TIMP-1 mRNA was measured. The expression of TIMP-1 mRNA in each group was as follows: $4.2 \pm 2.4$ in the control group, $4.8 \pm 2.0$ in the etodolac-treated group and 2.9 \pm 2.7 in the nimesulide-treated group (Fig. 4). No significant differences were noted between any of the groups. 


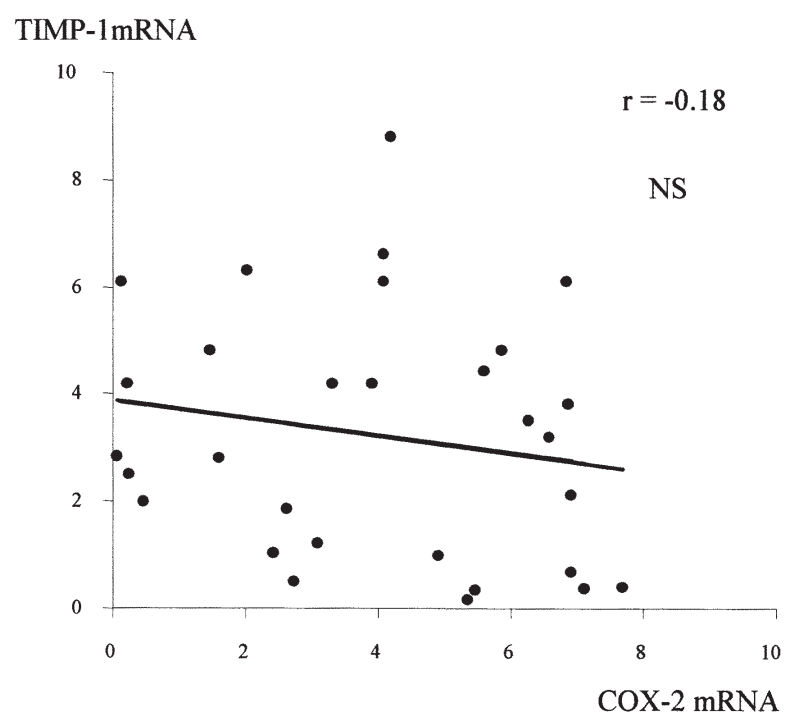

Figure 6. No correlation was recognized in the expression of COX-2 mRNA and TIMP-1 mRNA.

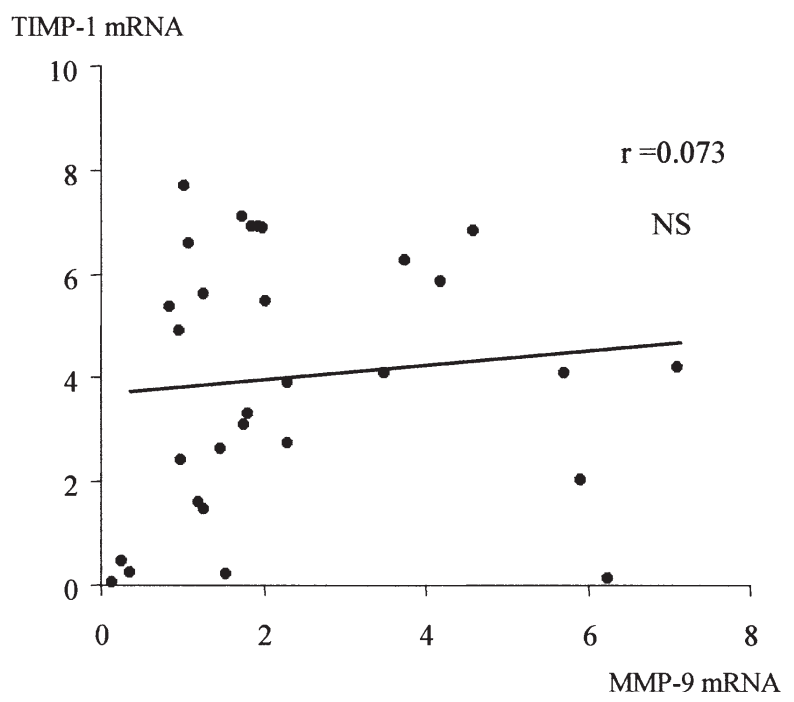

Figure 7. No correlation was recognized in the expression of MMP-9 mRNA and TIMP-1 mRNA.

Relationships among COX-2, MMP-9, and TIMP-2 mRNA. The relationships among COX-2 mRNA, MMP-9 mRNA and TIMP-1 mRNA were calculated by the Spearman rank correlation coefficient, respectively. There was a significant correlation between the expression of COX-2 mRNA and MMP-9 mRNA ( $r=0.78, p=0.001$ ) (Fig. 5), but no correlation between the expression of COX-2 mRNA and TIMP-1 mRNA (Fig. 6). In addition, the expression of MMP-9 mRNA did not correlate with that of TIMP-1 mRNA (Fig. 7).

\section{Discussion}

We set out to determine whether COX-2 inhibitor could have inhibitory effects on liver metastasis via MMP-9 suppression or TIMP-1 activation in colorectal cancer cells. Almost all the cancer cells that detach from the primary lesion and enter blood vessels are annihilated by the mechanical stress of blood flow and attack by the immune system centered on natural killer cells (20). In order to escape from this stress, the cancer cells created emboli of fellow cancer cells or emboli with lymph nodes, blood platelets, fibrin, etc. Cancer cells that reach remote organs bind gently with the selectin of endothelial cells of the blood vessel using sialyl Le $\mathrm{Le}^{\mathrm{a}}$ or sialyl Le $^{\mathrm{x}}$ on the surface of cancer cells, and roll over endothelial cells. Next, because of the stimulus of various cytokines produced by blood vessel endothelial cells, the integrin superfamily on cancer cell surface is activated and adheres forcefully to the immunoglobulin superfamily including ICAM-1 or VCAM-1 on blood vessel endothelial cell surface $(21,22)$. Then, cancer cells pass through cleavages of blood vessel endothelial cells and produce a strong bond with ECM, which forms the basement membrane under endothelial cells of the blood vessel (23). Kakiuchi et al (5), using in vitro human colorectal cancer cells, showed that COX-2 enhanced the expression of Span-1, a sialyl antigen on cancer cell surface, by increasing the expression of glycosyltransferase through production of PGE2, resulting in the increased ability of cancer cells to adhere to endothelial cells of the blood vessel. Moreover, in animal experiments, they injected cancer cells pretreated with celecoxib, a COX-2 inhibitor, or antiSpan-1 antibody into spleens and showed that, in both groups, hepatic metastasis was significantly suppressed compared with controls. These findings indicate that COX-2 inhibitor suppresses expression of the carbohydrate antigen and that adherence to blood vessel endothelium is reduced. In the present study, COX-2 inhibitor was administered from the day after cancer cell injection; thus, the incidence of cancer cell adherence to blood vessel endothelium is believed to be the same in both the control group and the COX-2 inhibitortreated group.

In the process of extravasation of cancer cells that have adhered strongly to endothelial cells of blood vessels, cancer cells degrade the basement membrane or ECM, then migrate through the cleavages, thus invading the surrounding area by means of the various proteases or glycosidases produced by the cancer cells themselves or by fibroblasts or other stromal cells. Of these enzymes, MMP-2 and MMP-9 play a pivotal role in the degradation of basement membrane, the main constituent of which is type IV collagen. Expression of MMP-2 or MMP-9 is induced at the transcriptional level by various cytokines or growth factors, and the enzymes are secreted as the latent form from cancer cells or stromal cells. Then the enzymes are activated by various proteases such as membrane-type matrix metalloproteinase (MT-MMP), plasmin or thrombin $(24,25)$. Using animal models of liver metastasis from colorectal cancer, several researchers reported on the inhibitory effect of various COX-2 inhibitors and the relationship between COX-2 inhibitors and MMPs (5-8). Yamauchi et al reported that, in mouse models of hepatic metastasis in which the human colorectal cancer cell line HT-29 or COLO205 was used, a COX-2 inhibitor, JTE-522, inhibited hepatic metastasis, but no association with COX-2 was recognized (6). Yao et al reported that, when NS-398, a COX-2 inhibitor, was cultivated in vitro with the mouse colorectal cancer cell line MC-26, there was a significant reduction in the protein expression and enzyme activity of 
MMP-2 and MMP-9 (7). They also pointed out that, in animal experiments, the incidence of liver metastasis was significantly reduced in the NS-398-treated group compared with controls on the 10th day after surgery but that there was no significant difference between the two groups on the 14th day after surgery. Furthermore, Nagatsuka et al (8) reported that, when LM-H3, a highly metastasizable colorectal cancer cell line, was used in nude mice, the COX-2 inhibitor, JTE-522, inhibited hepatic metastasis via PDGF or MMP-2. In the present study, the etodolac-treated group was found to have a significant decrease in number of hepatic metastatic nodules, COX-2 mRNA and MMP-9 mRNA, compared with the control group. In addition, there was a significant correlation between COX-2 mRNA and MMP-9 mRNA. These findings suggested that etodolac might weaken the ability of cancer cells to degrade basement membrane through a decrease of MMP-9 activity, resulting in the suppression of hepatic metastasis. Regarding the role of COX-2 in cancer metastasis and invasion, the precise mechanism remains obscure, but a decrease of COX-2-dependent PGE2 may downregulate MMP production via PGE2 receptors (26-29). On the contrary, no significant differences were noted in our study between the nimesulide-treated group and the control group in terms of the number of hepatic metastatic nodules or the expression of COX-2 mRNA and MMP-9 mRNA in tumors. Several reports indicated that influences on cancer growth, invasion and metastasis vary with the kind of COX-2 inhibitor and the cancer cell line (9,30,31). Accordingly, in clinical applications of COX-2 inhibitor for colorectal cancer, it is extremely important to know the distinguishing characteristics of the drugs used and the nature of the cancer.

In the physiological state, the activity of MMPs is controlled through the balance of various cytokines, growth factors (promoters) and TIMPs (inhibitors). In cancer tissue, however, it is suspected that this balance is disrupted, that MMPs become predominant, and that invasion and metastasis of cancer cells proceeds $(13,14)$. Ogata et al reported that, in experimental and clinical colorectal cancer, the expression of MMP-9 mRNA and TIMP-1 mRNA in tumor cells correlated with liver metastasis, but that there was no relation between the expression of these in stromal cells and liver metastasis (32). These findings suggested that the expression of MMP-9 mRNA and TIMP-1 mRNA in tumor cells is more closely related to the biological behavior of the tumor than is their expression in stromal cells. On the contrary, Joo et al reported that the immunoreactivity of TIMP-1 was markedly expressed in pericancer stromal cells, but that it was weak or negative in tumor cells or normal tissue (15). In addition, they showed that there was a significant association between the expression of TIMP-1 in stromal cells and Duke's stage, lymph node metastasis, and poor survival. In the present study, no significant difference was observed in the expression of TIMP-1 mRNA between the COX-2 inhibitor-treated group and the control group. Nor was a correlation recognized between the expression of COX-2 mRNA and TIMP-1 mRNA expression. Furthermore, there was no correlation between the expression of MMP-9 mRNA and TIMP-1 mRNA. Our findings showed that no correlation was recognized between hepatic metastasis and the expression of TIMP-1 mRNA in tumor cells. Since the precise mechanism of TIMP-1 remains obscure, further investigations are required by such means as animal experiments in which the induction of exogenous TIMP-1 mRNA is used $(33,34)$.

In conclusion, etodolac may suppress the ability of degradation of ECM or basement membrane under blood vessel endothelium via the decreased MMP-9 expression, resulting in the suppression of hepatic metastasis. Clinical trials with COX-2 inhibitor or MMP inhibitor are currently in progress $(35,36)$. In animal experiments, trials are underway with both MMP inhibitor and anti-cancer agents $(37,38)$. Consequently, it is expected that effective methods for preventing metastasis of colon cancer to the liver will be established.

\section{Acknowledgements}

We are indebted to Professor J. Patrick Barron of the International Medical Communications Center of Tokyo Medical University for his review of this manuscript.

\section{References}

1. Eberhart CE, Coffey RJ, Radika A, Giardiello FM, Ferrenbach S and Dubois RN: Up-regulation of cyclooxygenase 2 gene expression in human colorectal adenomas and adenocarcinoma. Gastroenterol 107: 1182-1188, 1994.

2. Kudo T, Narisawa T and Abo S: Antitumor activity of indomethacin on methylazoxymethanol-induced large bowel tumors in rats. Jpn J Cancer Res 71: 260-264, 1980.

3. Giovannucci E, Egan KM, Hunter DJ, Stampfer MJ, Colditz GA, Willett WC and Speizer FE: Aspirin and the risk of colorectal cancer in women. N Engl J Med 333: 609-614, 1995.

4. Tomozawa S, Nagawa H, Tsuno N, Hatano K, Osada T, Kitayama J, Nita ME, Ishihara S, Yano H, Tsuruo T, Shibata Y and Muto T: Inhibition of haematogenous metastasis of colon cancer in mice by a selective COX-2 inhibitor, JTE-522. Br J Cancer 81: 1274-1279, 1999.

5. Kakiuchi Y, Tsuji S, Tsujii M, Murata H, Kawai N, Yasumaru M, Kimura A, Komori M, Irie T, Miyoshi E, Sasaki Y, Hayashi N, Kawano S and Hori M: Cyclooxygenase-2 activity altered the cell-surface carbohydrate antigens on colon cancer cells and enhanced liver metastasis. Cancer Res 62: 1567-1572, 2002.

6. Yamauchi T, Watanabe M, Hasegawa H, Nishibori H, Ishii Y, Tatematsu H, Yamamoto K, Kubota T and Kitajima M: The potential for a selective cyclooxygenase-2 inhibitor in the prevention of liver metastasis in human colorectal cancer. Anticancer Res 23: 245-250, 2003.

7. Yao M, Lam EC, Kelly CR, Zhou W and Wolfe MM: Cyclooxygenase-2 selective inhibition with NS-398 suppresses proliferation and invasiveness and delays liver metastasis in colorectal cancer. Br J Cancer 90: 712-719, 2004.

8. Nagatsuka I, Yamada N, Shimizu S, Ohira M, Nishino H, Seki S and Hirakawa K: Inhibitory effect of a selective cyclooxygenase-2 inhibitor on liver metastasis of colon cancer. Int J Cancer 100: $515-519,2002$.

9. Matsunaga N, Yamada N, Ohira M, Tachimori A, Nishiguchi Y, Nishino H, Seki S and Hirakawa K: Combined treatment with selective cyclooxygenase-2 inhibitor and fluorinated pyrimidines for liver metastasis of colon cancer. Oncol Rep 11: 167-171, 2004.

10. Ishikawa T, Ichikawa Y, Mitsuhashi M, Momiyama N, Chishima T, Tanaka K, Yamaoka H, Miyazaki K, Nagashima Y, Akitaya T and Shimada H: Matrilysin is associated with progression of colorectal tumor. Cancer Lett 107: 5-10, 1996.

11. Guo H, Zucker S, Gordon MK, Toole BP and Biswas C: Stimulation of matrix metalloproteinase production by recombinant extracellular matrix metaproteinase induced from transfected Chinese hamster ovary cells. J Biol Chem 272: 23-27, 1997.

12. Somasundaram K, Jayaraman G, Williams T, Moran E, Frisch S and Thimmapaya B: Repression of a matrix metalloprotease gene by E1A correlates with its ability to bind to cell typespecific transcription factor AP-2. Proc Natl Acad Sci USA 93: 3088-3093, 1996. 
13. Yoshizaki T, Sato H and Furukawa M: Recent advances in the regulation of matrix metalloproteinase 2 activation: from basic research to clinical implication (Review). Oncol Rep 9: 607-611, 2002.

14. Liotta LA, Steeg PS and Stetler-Stevenson WG: Cancer metastasis and angiogenesis: an imbalance of positive and negative regulation. Cell 64: 327-336, 1991.

15. Joo TE, Seo KS, Kim J, Kim HS, Rew JS, Park CS and Kim SJ: Role of tissue inhibitors of metalloproteinases (TIMPs) in colorectal carcinoma. J Korean Med Sci 14: 417-423, 1999.

16. Iishi H, Tatsuta M, Baba M, Yano H, Higashino K, Mukai M and Akedo H: Suppression by nimesulide of Bombesin-enhanced peritoneal metastasis of intestinal adenocarcinomas induced by azoxymethane in Wister rats. Clin Exp Metastasis 20: 555-560, 2003.

17. Kinugasa $Y$, Hatori M, Ito H, Kurihara Y, Ito D and Nagumo M: Inhibition of cyclooxygenase-2 suppresses invasiveness of oral squamous cell carcinoma cell lines via down-regulation of matrix metalloproteinase-2 and CD44. Clin Exp Metastasis 21: 737-745, 2004.

18. Symowics J, Adley BP, Woo MM, Auersperg N, Hudson LG and Stack MS: Cyclooxygenase functions as a downstream mediator of lysophosphatic acid to promote aggressive behavior in ovarian carcinoma cells. Cancer Res 65: 2234-2242, 2005.

19. Lee HC, Park IC, Park MJ, An S, Woo SH, Jin HO, Chung HY, Lee SJ, Gwak HS, Hong YJ, Yoo DH, Rhee CH and Hong SI: Sulindac and its metabolites inhibit invasion of glioblastoma cells via down-regulation of Akt/PKB and MMP-2. J Cell Biochem 94: 597-610, 2005.

20. Fidler IJ: Metastasis: quantitative analysis of distribution and fate of tumor emboli labeled with 125I-5-iod-2'-deozyurine. J Natl Cancer Inst 45: 773-782, 1970

21. Picker LJ, Warnock RA, Burns AR, Doerschuk CM, Berg EL and Butcher EC: The neutrophil selectin LECAM-1 presents carbohydrate ligands to the vascular selectins ELAM-1 and GMP-140. Cell 66: 921-933, 1991.

22. Huber AR, Kunkel SL, Todd RF III and Weiss SJ: Regulation of transendothelial neutrophil migration by endogeneous interleukin-8. Science 254: 99-102, 1991.

23. Lawrence MB and Springer TA: Leukocytes roll on a selectin at physiologic flow rates: distinction from and prerequisite for adhesion through integrins. Cell 65: 859-873, 1991.

24. Baramova EN, Bajou K, Remacle A, L'Hoir C, Krell HW, Weidle UH, Noel A and Foidart JM: Involvement of PA/ plasmin system in the processing of pro-MMP-9 and in the second step of pro-MMP-2 activation. FEBS Lett 405: 157-162, 1997.

25. Zucker S, Conner C, Di Massmo BI, Ende H, Drews M, Seiki M and Bahou WF: Thrombin induces the activation of progelatinase A in vascular endothelial cells. Physiologic regulation of angiogenesis. J Biol Chem 270: 23730-23738, 1995.

26. Dohadwala M, Batra RK, Luo J, Lin Y, Krysan K, Pold M, Sharma S and Dubinett SM: Autocrine/paracrine prostaglandin E2 production by non-small cell lung cancer cells regulates matrix metalloproteinase-2 and CD44 in cyclooxygenase-2 dependent invasion. J Biol Chem 277: 50828-50833, 2002.
27. Miyamoto $\mathrm{H}$, Altuwaijri S, Messing EM and Chang $\mathrm{C}$ Inhibition of the Akt, cyclooxygenase-2, and matrix metalloproteinase-9 pathways in combination with androgen deprivation therapy: potential therapeutic approaches for prostate cancer. Mol Carcinog 44: 1-10, 2005.

28. Ito H, Duxbury M, Benoit E, Clancy TE, Zinner MJ, Ashley SW and Whang EE: Prostaglandin E2 enhances pancreatic cancer invasiveness through an Ets-1-dependent induction of matrix metalloproteinase-2. Cancer Res 64: 7439-7446, 2004.

29. Yan M, Noguchi K, Ruwanpura SM and Ishikawa I: Cyclooxygenase-2-dependent prostaglandin (PG) E2 downregulates matrix metaproteinase-3 production via EP2/Ep4 subtypes of PGE2 receptors in human periodontal ligament cells stimulated with interleukin-1 alpha. J Periodontol 76: 929-935, 2005.

30. Chen WS, Wei SJ, Liu JM, Hsio M, Kou-Lin J and Yang WK: Tumor invasiveness and liver metastasis of colon cancer cells correlated with cycloxygenase-2 (COX-2) expression and inhibited by a COX-2-selective inhibitor, etodolac. Int J Cancer 92: 894-899, 2001.

31. Yamazaki R, Kusunoki N, Matsuzaki T, Hashimoto S and Kawai S: Selective cyclooxygenase-2 inhibitors show a differential ability to inhibit proliferation and induce apoptosis of colon adenocarcinoma cells. FEBS Lett 531: 278-284, 2002.

32. Ogata T, Miura K, Ohkita A, Nagase H and Shirouzu K: Imbalance between matrix metalloproteinase 9 and tissue inhibitor of metalloproteinases 1 expression by tumor cells implicated in liver metastasis from colorectal carcinoma. Kurume Med J 48: 211-218, 2001.

33. Yamauchi K, Ogata Y, Nagase H and Shirouzu K: Inhibition of liver metastasis from orthotopically implanted colon cancer in nude mice by transfection of the TIMP-1 gene into KM12SM cells. Surg Today 31: 791-798, 2001.

34. Ikenaka Y, Yoshiji H, Kuriyama S, Yoshii J, Noguchi R, Tsujinoue H, Yanase K, Namisaki T, Imazu H, Masaki T and Fukui H: Tissue inhibitor of metalloproteinase-1 (TIMP-1) inhibits tumor growth and angiogenesis in the TIMP-1 transgenic mouse model. Int J Cancer 105: 340-346, 2003.

35. Wall L, Talbot DC, Bradbury P and Jodrell DI: A phase I and pharmacological study of the matrix metalloproteinase inhibitor BB-3644 in patients with solid tumours. Br J Cancer 90: 800-804, 2004.

36. Rizvi NA, Humphrey JS, Ness EA, Johnson MD, Gupta E, Williams K, Daly DJ, Sonnichsen D, Conway D, Marshall J and Hurwitz H: A phase I study of oral BMS-275291, a novel nonhydroxamate sheddase-sparing matrix metalloproteinase inhibitor, in patients with advanced or metastatic cancer. Clin Cancer Res 10: 1963-1970, 2004

37. Yamamoto A, Yano S, Shiraga M, Ogawa H, Goto H, Miki T, Zhang $\mathrm{H}$ and Sone S: A third-generation matrix metalloproteinase (MMP) inhibitor (ONO-4817) combined with docetaxel suppresses progression of lung micrometastasis of MMP-expressing tumor cells in nude mice. Int J Cancer 103: 822-828, 2003.

38. Eatock M, Cassidy J, Johnson J, Morrison R, Devlin M, Blackey R, Owen S, Choi L and Twelves C: A dose-finding and pharmacokinetic study of the matrix metalloproteinase inhibitor MMI270 (previously termed CGS27023A) with 5-FU and folinic acid. Cancer Chemother Pharmacol 55: 39-46, 2005. 